\title{
Policy Mandates and Institutional Architecture
}

\author{
Ioannis Lazopoulos* $\quad$ Vasco Gabriel ${ }^{\dagger}$ \\ January 11, 2019
}

\begin{abstract}
The model developed in this paper examines the interaction between monetary and macroprudential policies in promoting macroeconomic stability, highlighting the role of shocks and policy instruments. The paper shows that assigning the mandates of monetary and financial stability to independent authorities enhances macroeconomic stability only when some level of coordination exists between policymakers and it is the dominant institutional arrangement when monetary stability is socially important. Instead, when society values financial stability, internalising the policy spillovers by assigning the two mandates to a single policymaker could become the dominant configuration depending on the model's parameter values.
\end{abstract}

JEL classification: E42; E44; E52; E58; E61

Keywords: Monetary policy; Macroprudential policy; Institutional mandates; Policy coordination

${ }^{*}$ School of Economics, University of Surrey, Surrey GU2 7XH, UK.

${ }^{\dagger}$ School of Economics, University of Surrey, Surrey GU2 7XH, UK. 


\section{Introduction}

The worldwide economic contraction that followed the aftermath of the 2007 financial crisis demonstrated the extent to which systemic risk has been underestimated by policymakers. Soon after that, financial institutions' liquidity and solvency problems became systemic, resulting in a significant impact on the real economy. The reform of the international regulatory framework that followed aims to promote the safety and soundness of the financial system and encourage the endorsement of macroprudential policies in an attempt to insulate the economy from financial risks. Although the microprudential recommendations introduced by Basel III have been widely accepted, there is no clear consensus among policymakers on the conduct of macroprudential policy due to the equivocal welfare effects that result from the interaction with monetary policy. Evidently, this debate has a profound effect on shaping the institutional architecture of policymaking that is adopted around the world, as in some countries the mandate of financial stability is designated to the central banks, while in others it has been assigned to separate authorities.

The aim of this paper is to explore the influence that the interdependencies between monetary and macroprudential policies have on macroeconomic stability that shapes the institutional structure of policymaking. Introducing a banking sector in a stylised macroeconomic setting, the paper develops a model that captures the spillover effects that instruments have on policymakers' objectives in a tractable manner by analysing the policy transmission channels. In a static setting, it is shown that separation of mandates can only be the dominant arrangement when monetary stability is more socially desirable than financial stability, whereas the instrument choice for a policymaker with a dual mandate depends on the type of shock the economy experiences. Extending the model in a dynamic setting, separation of mandates with policy coordination is the dominant institutional setting for a wide range of the model's parameters.

\subsection{Related Literature and Contribution}

Historically, central banks have been the implicit guarantors of financial stability as lenders of last resort. After the late nineties, however, empirical evidence demonstrate a tendency of OECD countries to change the institutional design of policymaking by separating the price and financial stability mandates and assigning the latter to an independent authority (Pellegrina et al. 2013). Recent changes on the institutional landscape following the 2007 crisis have revived the debate on the optimal design of policymaking.

Despite the numerous arguments for and against the separation of the two mandates present in the literature, ${ }^{\square}$ the effectiveness of the institutional structure is determined by its ability to attain the designated policy goals, which in turn depends on the interaction of macroeconomic policies. Indeed, monetary targets can be affected by responding to financial market distortions in the pursuit of financial stability, and equivalently prudential targets can be influenced by monetary policy that aims to stabilise inflation. In particular, the policy rate may not fully

\footnotetext{
${ }^{1}$ Recognising serious failures following the events of the recent crisis, the prudential regulation in the UK returned to the Bank of England (Financial Services Act, 2012) after being assigned to the Financial Services Authority (Bank of England Act, 1998). In contrast, prudential regulation in the US is designated to the Financial Stability Oversight Council (Dodd-Frank Act, 2010) which is independent of the Fed, while the European Commission created the European Systemic Risk Board in 2010 which is independent of ECB.

${ }^{2}$ Vickers (2002) points out the organisational differences involved in accomplishing the two objectives, while Goodhart and Schoenmaker (1993, 1995) argue that establishing an independent regulator accountable for financial stability reduces the monetary policymaker's reputational risk and government's political risk in the event of a financial crisis. In contrast, gains from a unified framework arise from the expertise of the human capital employed and the costly information produced (Peek et al, |1999). See also Doumpos et al. (2015).
} 
adjust to combat inflation, as this could have adverse effects on banks' liquidity and solvency due to the maturity mismatch between their assets and liabilities ${ }^{\mathbb{B}}$ and even encourage precarious behaviour through the risk-taking channel as first identified by Borio and Zhu (2012). The empirical findings suggests that the monetary policy stance has a profound effect on the prices of financial assets, credit standards of banks' asset portfolio (Ciccarelli et al. 2015), perceived risks by market participants (Altunbas et al. 2014) and banks' general risk-taking behaviour (Neuenkirch and Nöckel 2018) that necessitates a policy response by the prudential regulator. Such negative externalities can be reduced by assigning the financial stability mandate to an independent authority with additional instruments following the Tinbergen principle, or alternatively by becoming internalised within a single authority when policy coordination is limited.

The design of macroeconomic policymaking has recently become an increasing are of research interest with no apparent consensus. A strand of the Dynamic Stochastic General Equilibrium (DSGE) literature focuses on the welfare consequences of the interplay between monetary and macroprudential policies. ${ }^{\text {TI }}$ In particular, Angelini et al. (2014) show that there are sizeable benefits from separation of price and financial stability mandates when the economy is subjected to financial shocks, independent of the level of coordination between the two authorities. However, coordination reduces welfare losses when the economy experiences supply shocks by decreasing instrument volatility, while the benefits remain moderate in comparison to the central banks' single mandate of price stability. Tayler and Zilberman (2016) also highlight the need for policy coordination in response to supply rather than credit shocks. Moreover, Rubio and Carrasco-Gallego (2014) show that policy coordination in response to a collateral value shock improves social welfare contrary to a technology shock. By considering a variety of shocks, Beau et al (2012) find no conflict between monetary and macroprudential policies as price stability is not affected by the institutional arrangements. When banks are subject to runs due to the uncertainty about their assets' returns, Angeloni and Faia (2013) show that there are welfare gains from coordination when the monetary policymaker reacts to financial conditions, while Collard et al. (2017) argue that risk-taking due to the inherent moral hazard problems calls for greater policy coordination. While most of the findings of the relevant DSGE literature are based on calibrated models, Gelain and Ilbas (2017) estimate a DSGE model with US data and conclude that benefits from coordination arise only when the common objective of output gap stabilisation receives similar importance in both mandates.

Findings are also inconclusive in the empirical literature that examines whether central banks' actions are influenced by macroprudential responsibilities. In particular, controlling only for the degree of central banks' independence, DiNoia and DiGiorgio (1999) find evidence that separation of the financial stability mandate has a significant negative effect on inflation for 25 industrialised countries over the period 1960-1996. Copelovitch and Singer $(2008)$ find the same effect conditional on the exchange rate regime and banking sector size. While extending the time span up to 2012 to capture countries that have changed their institutional mandates more than once, Lima et al. (2016) do not find any evidence that separation of mandates is associated with lower inflation rates when estimating a dynamic panel with fixed effects. Moreover, Ioannidou (2005) shows that the Fed's monetary stability mandate influenced its macroprudential actions during 1990-1998. However, Aiyar et al. (2016) conclude that, contrary to capital requirements, the policy rate had a small effect on banks' credit

\footnotetext{
${ }^{3}$ Goodhart and Schoenmaker (1993, 11995) provide evidence suggesting that interest rates were kept low during the Savings and Loans crisis in the 90s in the US in fear of the adverse effects that higher rates have on the institutions' solvency.

${ }^{4} \mathrm{~A}$ review of the literature can be found in Galati and Moessner (2013).
} 
provision in the UK during 1998-2007 as evidence of minimal interaction between the policy instruments and the associated monetary and macroprudential policies.

The present paper contributes to the line of work on optimal institutional design of policymaking. Departing from the commonly used estimated and calibrated models, the paper develops a simple theoretical set up to study the role of policy mandates' allocation on optimal macroeconomic policy. By introducing a banking sector as in Cecchetti and Li (2008) in a stylised macroeconomic framework commonly employed for policy analysis (see Bernanke and Blinder 1988 and Svensson 1997, 1999), the interaction between monetary and macroprudential policies is captured in a tractable manner that enables a comparative static analysis. In this way, the model identifies the role of different parameters in determining the optimal policy design, consolidating some of the divergent results of the empirical and simulated studies in the literature.

The institutional configurations considered are characterised by the allocation of policy mandates without imposing restrictions on instrument availability. Contrary to the generally endorsed monetary policy objective of price stability that is clearly defined and measured, the objective of macroprudential policy does not have a widely accepted definition or a quantifiable measurement. The literature suggests several indicators of financial distress that policymakers should respond to in order to prevent general risk-taking and adjust banks' lending to business cycle. In this model, the macroprudential objective is captured by the spread of the lending and funding (policy) rate that represent the cost of borrowing of different economic agents and has a direct effect on aggregate demand so that changes in the credit spread could lead to financial imbalances that threaten financial stability. ${ }^{\text {[ }}$ In line with traditional literature, both policy mandates are described in terms of quadratic loss functions.

Capital requirements is introduced as another stabilisation policy tool that affects the real economy by having a direct effect on the balance sheet of the banking sector. The model shows that capital requirements' adjustment is more effective at influencing the lending market in the pursuit of financial stability than the policy rate as suggested by empirical findings, whereas the latter instrument is more effective in promoting monetary stability. ${ }^{\square}$ Thus, the optimal institutional configuration is determined by society's preferences over the two mandates and the size of spillover effects that the instruments have on policy objectives.

In the static version of the model, it is shown that for a policymaker with a dual mandate, the preferred instrument is determined by the interaction of policy transmission channels and depends on the type of shock that the economy experiences. As such, adjustments in the policy rate following an aggregate demand shock, or in capital requirements following an aggregate supply or financial shocks, lead to an improvement on monetary and financial stability, constituting the two policy objectives as complementary. When mandates are separated, macroeconomic stability improves once the independent authorities coordinate their actions, so that the monetary policymaker's response takes into account the spillover effects of macroprudential policy on macroeconomic variables. Overall, the optimal institutional design depends on society's preferences, as separation of policy mandates enhances macroeconomic stability when inflation stability is more socially desirable, and a dual mandate for a single authority when the society values more financial stability. Capital requirements is the preferred policy instrument

\footnotetext{
${ }^{5}$ Some of these variables include banks' credit growth (Gelain and Ilbas 2017), credit relative to the size of the economy (Angelini et al. 2012, 2014), leverage ratio (Angeloni and Faia 2013, Valencia 2014), loan-to-value ratio (Beau et al. 2012, Rubio and Carrasco-Gallego 2014) and credit spreads (Curdia and Woodtord 2010, Woodford 2012, Cecchetti and Kohler 2014, Tayler and Zilberman 2016), among others.

${ }^{6} \mathrm{~A}$ discussion on the role of credit spreads in the money markets during the 2007-09 crisis and sovereign debt crisis that followed can be found in Taylor and Williams (2009) and Arellano et al (2016), respectively.

${ }^{7}$ See Bridges et al. (2014) and Aiyar et al. (2014).
} 
in response to financial shocks.

Extending the model in a dynamic setting, the policy rate is always the optimal instrument as capital requirements' adjustments result in excess volatility of the macroeconomic variables. Similar to the static case, coordination between independent authorities is the dominant setting when monetary stability is socially important, while a policymaker with a dual mandate could become the dominant arrangement when social preferences are such that a greater weight is placed on financial stability.

The rest of the paper proceeds as follows. Section $\square$ develops a theoretical framework for the static version of the economy, while the evaluation of alternative institutional structures is performed in Section [3. Section 1 extends the model to a dynamic setting and identifies the optimal institutional arrangements. Section 6 concludes.

\section{The Model}

We consider a standard macroeconomic framework that incorporates a banking sector as in Cecchetti and Li (2008), written as log-linear deviations from the steady state. For tractability and without loss of generality, the model considered is in line with the traditional aggregate demand-aggregate supply models commonly used for policy analysis (see Bernanke and Blinden 1988 and Svensson 1997, 1999) and consistent with micro-founded models and empirical findings via parameter restrictions.

Financial intermediation is introduced by allowing banks to influence the level of economic activity. Following Bernanke and Blinder (1988), aggregate demand $y^{d}$ is influenced by both a policy-controlled rate $i$ and a market determined lending rate $\rho$, and along with aggregate supply $y^{s}$ are given by

$$
\begin{aligned}
& y^{d}=-a_{\pi} \pi-a_{i}\left(i-\pi^{e}\right)-a_{\rho}\left(\rho-\pi^{e}\right)+h \\
& y^{s}=\beta\left(\pi-\pi^{e}\right)+\epsilon,
\end{aligned}
$$

where $\pi$ is inflation, $\pi^{e}$ denotes expected inflation, while potential output is normalised to zero and the parameters $a_{\rho}, a_{i}$ and $a_{\pi}$ are positive. Aggregate demand and supply shocks are represented by the white noise variables $h$ and $\epsilon$, respectively, that are uncorrelated with each other. Agents are assumed to be unaware of the macroeconomic shocks and have rational expectations so that $\pi^{e}$ is zero. In addition, for tractability of the analysis that follows, $y^{s}$ is considered to be inelastic with respect to inflation such that $\beta \in(0,1]$.

The two rates that suppress aggregate expenditure represent short-term interest rates faced by heterogeneous economic agents. As in Curdia and Woodford (2010) and Woodford (2012), the type of agents depends on whether they are financially constrained. Agents that are not financially constrained are rewarded by receiving the policy rate $i$ on their financial surpluses whereas credit-constrained agents borrow at rate $\rho$ that is determined in a loan market. Credit frictions establish a role for macroprudential policy and capital requirements $k$ that influences banks' lending is introduced as another policy instrument.

Specifically, by controlling the availability of credit, banks can influence the price of credit in the economy that is established in the loan market and described by

$$
\begin{aligned}
& \ell^{d}=-\ell_{\rho}\left(\rho-\pi^{e}\right)+\ell_{y} y+\eta \\
& \ell^{s}=c y-k+e .
\end{aligned}
$$

The loan demand $\ell^{d}$ depends negatively on the lending rate $\rho$ and positively on output $y$. The loan supply $\ell^{s}$ depends negatively on capital requirements $k$ and positively on banks' capital $c y$, 
which increases with $y$ as a greater number of loan repayments when the economy is expanding contributes to the higher net worth of the banking sector, while parameters $c, \ell_{\rho}$ and $\ell_{y}$ are positive. Financial shocks denoted by $\eta$ and $e$ that affect $\ell^{d}$ and $\ell^{s}$, respectively, are uncorrelated white noise variables. Without loss of generality, the banking sector is considered to be capital constrained, which could reflect binding liquidity constraints (Bernanke and Gertler 1995), banks' attempts to maintain their capital buffers (Van den Heuvel 20(2)), or simply the high costs involved in raising equity capital as suggested by empirical findings (Aiyar et al. 2014). This assumption simplifies the analysis as changes in $k$ have a univocal effect on $\ell^{s}$.

Substituting for the equilibrium lending rate, inflation and output gap are linear functions of the shocks and policy instruments

$$
\begin{aligned}
& \rho=\frac{k}{\ell_{\rho}}+y \theta+H \\
& \pi=-\left(\frac{a_{i}}{r}\right) i-\left(\frac{a_{\rho}}{\ell_{\rho} r}\right) k-\left(\frac{1+a_{\rho} \theta}{r}\right) \epsilon+\left(\frac{1}{r}\right) h-\left(\frac{a_{\rho}}{r}\right) H \\
& y=-\left(\frac{a_{i} \beta}{r}\right) i-\left(\frac{a_{\rho} \beta}{\ell_{\rho} r}\right) k+\left(\frac{a_{\pi}}{r}\right) \epsilon+\left(\frac{\beta}{r}\right) h-\left(\frac{a_{\rho} \beta}{r}\right) H
\end{aligned}
$$

where $\theta=\left(\ell_{y}-c\right) / \ell_{\rho}$ measures the sensitivity of the equilibrium lending rate to changes in output, while $H=(\eta-e) / \ell_{\rho}$ and $r=\beta\left(1+a_{\rho} \theta\right)+a_{\pi}$ to simplify notation. In order for the shocks to have the predicted effects on the macroeconomic variables, it is assumed that $\ell^{d}$ is more sensitive to changes in output than $\ell^{s}$ so that $\ell_{y}-c>0$, which implies that $\theta>0$ and therefore $r>0$. Regarding the policy mandates, the policymaker in charge of monetary stability aims to minimise deviations of inflation from a targeted value, but not at the detriment of output stabilisation as deviations of output from its potential level are also of concern. Following the traditional literature, this is captured by the minimisation problem of the quadratic loss function

$$
L_{M P}=\pi^{2}+\lambda y^{2},
$$

where targeted inflation is assumed zero for simplicity and $\lambda \in(0,1]$ is the policymaker's inflation aversion. ${ }^{\mathbb{8}}$

Contrary to the widely endorsed goals of monetary policymaking, the macroprudential objectives are not well-established in the literature. Focusing on the asset side of banks' balance sheet as credit creation is associated with financial imbalances, many of the suggested macroprudential objectives aim to restrict banks' credit growth, adjust lending to the business cycle and discourage risk-taking behaviour. ${ }^{\square}$ In this model, financial instability is captured by the spread between the lending and the policy rate as in Cecchetti and Kohler (2014), since deviations of the cost of capital from the opportunity cost of capital can lead to financial imbalances. Policymakers aim to minimise the following loss function

$$
L_{F S}=(\rho-i)^{2}
$$

The analysis commences by examining the setting of a single policymaker with two objectives and two instruments to account for the spillover effects on macroeconomic stability that

\footnotetext{
${ }^{8}$ Following Woodford $\left.(20) 3\right)$, the literature advocates that a small weight should be assigned to measures of economic activity in the objective of welfare-maximising monetary policymakers. More recently, however, this view has become a subject of debate (see Debortoli et al. 2017).

${ }^{9}$ In addition to the aforementioned DSGE literature, see also Kahou and Lehar (2017) for a survey on macroprudential policies and objectives.
} 
result from policy interactions. This case acts as a benchmark in comparing alternative institutional configurations by evaluating the policies that minimise an aggregate loss function while considering the features that characterise each setting. Although optimal policies are derived in an ad-hoc fashion that is convenient for obtaining analytical results, the tractability of the model enables a comparative static analysis that identifies the role of the model's parameters and weights assigned on stability mandates in determining the preferred configuration. ${ }^{\mathbb{1 0}}$ The optimisation problem is written as

\section{General Optimisation Problem (Static).}

$$
\begin{gathered}
\min _{i, k} L:=\zeta L_{F S}+(1-\zeta) L_{M P} \\
\text { subject to (四), (田) and (回), }
\end{gathered}
$$

where $\zeta \in[0,1]$ is the weight attached to financial stability and reflects the policymakers' preferences over the two objectives. Let $k_{f}$ and $i_{f}$ be the (first-best) solutions to the above optimisation problem that satisfy the first-order conditions

$$
\begin{aligned}
& \zeta(\rho-i) \partial \rho / \partial k+(1-\zeta)(\pi+\lambda \beta y) \partial \pi / \partial k=0 \\
& \zeta(\rho-i)(\partial \rho / \partial i-1)+(1-\zeta)(\pi+\lambda \beta y) \partial \pi / \partial i=0 .
\end{aligned}
$$

To simplify the notations, let $\Phi_{k}\left(k_{f}, i_{f} ; \zeta\right)$ and $\Phi_{i}\left(k_{f}, i_{f} ; \zeta\right)$ denote the first-order conditions with respect to $k$ and $i$, respectively. They are written as implicit functions of the two instruments and the parameter $\zeta$, and simultaneously satisfied for $\pi\left(k_{f}, i_{f}\right)=-\lambda \beta y\left(k_{f}, i_{f}\right)$ and $\rho\left(k_{f}, i_{f}\right)=i_{f}$. As these relationships between macroeconomic variables hold regardless of the instrument used, there is perfect instrument substitutability which is due to the linearity of the model and the quadratic form of the loss functions. ${ }^{\square}$ In addition, as $\pi\left(k_{f}, i_{f}\right)$ and $y\left(k_{f}, i_{f}\right)$ depend on $\epsilon$, only aggregate supply shocks have a real effect on the economy. Indeed, the effect of aggregate demand and financial shocks on output can be counterbalanced by adjusting either instrument such that the spread between the policy and lending rate remains unchanged. Analytically, $y\left(k_{f}, i_{f}\right)=\epsilon /\left(1+\lambda \beta^{2}\right)$ so that a positive supply shock leads to an increase in output and a fall in inflation as expected.

Finally, the linearity of aggregate loss function in $\zeta$ implies that the first-best solution is independent of the weight placed on stabilisation policies. Therefore, $\left(k_{f}, i_{f}\right)$ is also the solution to the optimisation problem of a social planner as the public could have different preferences over the two objectives, allowing for the weights attached to the simple policy objectives considered to be loosely defined. Substituting $y\left(k_{f}, i_{f}\right)$ and $\pi\left(k_{f}, i_{f}\right)$ into (B)), the optimal policy rules are

$$
i_{f}=-\left(\frac{1-\lambda \beta a_{\pi}}{\left(a_{\rho}+a_{i}\right)\left(1+\lambda \beta^{2}\right)}\right) \epsilon+\left(\frac{1}{a_{\rho}+a_{i}}\right) h \text { and } k_{f} / \ell_{\rho}=i_{f}-\left(\frac{\theta}{1+\lambda \beta^{2}}\right) \epsilon-H .
$$

Both $i_{f}$ and $k_{f}$ respond positively to $h$ as expected, damping the effect of the shock on output and inflation. In contrast, the two instruments are expected to respond negatively to $\epsilon$ as inflation-averse policymakers attempt to stabilise inflation as shown in (B)). Therefore, it is required that the model's parameters satisfy $\lambda \beta a_{\pi}<1$, which restricts the values that the inflation elasticity of aggregate demand can take, provided that the policymaker is inflation-averse and

\footnotetext{
${ }^{10}$ Following Woodtord (20(03)'s seminal work, quadratic loss functions have been used to approximate households' objective, providing a welfare based criterion in the design of simple policy objectives, where policy weights are determined by the specific features of the economy in calibrated models of any scale.

${ }^{11}$ This feature has also been highlighted by Cecchetti and Kohlen (2014).
} 
output has a low sensitivity to changes in inflation. Finally, $k_{f}$ adjusts to insulate the economy against financial shocks.

The evaluation of the configurations considered in the rest of the paper involves settings where policymakers have one instrument under control. This consideration stems from the observation that $i$ is adjusted more frequently than $k$, as the resulting uncertainty from recurring adjustments of the latter policy instrument could influence the price of credit by disrupting its availability, which in turn increases the liquidity and credit risk due to the maturity mismatch between banks' assets and liabilities. This is evident by the frequency of adjustment of macroprudential policy relative to monetary policy and in accordance with the existing literature that models the central bank's instrument as a traditional or augmented Taylor rule to capture the effects of a policy response to financial variables. In contrast, macroprudential regulators are considered focusing on the policy goal with the instrument at hand following a normative approach (see Angeloni and Faia 2013, Angelini et al. 2014). Without imposing an association between objectives and instruments by allowing policymakers to be instrument independent, the requirement of one instrument imposes an additional restriction to the optimisation problem of a single policymaker. However, when mandates are separated, the outcome depends on the policymakers' strategic interactions.

\subsection{Combined Mandates}

A policymaker with a single instrument is not able to optimally pursue both objectives and the first-best outcome is no longer attainable. As transmission channels are linked through the lending rate, a change in either instrument will affect both policy goals which yield inferior outcomes. In this case, the policy rules are given by the first-order conditions where $\Phi_{k}(0, k ; \zeta)$ and $\Phi_{i}(i, 0 ; \zeta)$. As the optimisation problem cannot be distinguished according to the two objectives, the optimal policy rules depend on $\zeta$.

\subsection{Separate Mandates}

The incurred losses associated with the instruments' spillover effects on policy goals could be reduced by separating the two mandates, providing policymakers with greater flexibility to pursue their objectives. Under full coordination, by considering the interdependence of their decisions, policymakers can be viewed as to jointly minimise the aggregate loss function and therefore the resulting equilibrium is the first-best solution. The optimal policy rules are $\Phi_{k}\left(i_{f}, k_{f} ; 1\right)$ and $\Phi_{i}\left(i_{f}, k_{f} ; 0\right)$. However, as previously argued, although this setting provides very useful insights to the model, it is not considered to be implementable.

Instead, the cases of complete and partial separation of policy mandates are examined which are characterised by limited coordination. In particular, in the case where mandates are completely separated, policymakers are considered to minimise their objective function ignoring the possible effects by the other policymaker's response. Lack of coordination implies that policy decisions are independent and therefore the first-best outcome is no longer attainable as the spillover effects are ignored. In contrast, when mandates are partially separated, one of the policymakers is fully rational and takes the behaviour of the other into account in setting the instrument at the optimal level. Even though the timing of moves does not affect the results as the first-best outcome remains a solution for separate policymakers, instruments are considered to be set sequentially to capture the difference in the regularity of instruments' adjustment. Indeed, the macroprudential regulator is considered to move first as the decision to set $k$ in pursuing financial stability is independent of $i$, whereas the monetary policymaker can optimally respond to any changes in $k$ by adjusting $i$. 


\section{Policy Evaluation in the Static Setting}

The institutional configurations that are evaluated include a dual mandate where the policy instrument is $i$ or $k$, and complete $(S)$ or partial $(R)$ separation of mandates, with the monetary policymaker having the second-mover advantage. Let these settings be indexed by $j \in\{i, k, S, R\}$, where $L^{j}$ denotes the corresponding value function and $L^{j j^{\prime}}$ the difference in the aggregate loss between any two settings $j \neq j^{\prime}$ such that

$$
L^{j j^{\prime}}=z\left(L_{F S}^{j}-L_{F S}^{j}\right)+(1-z)\left(L_{M P}^{j}-L_{M P}^{j^{\prime}}\right),
$$

where $z$ is the society's weight placed on financial stability, which can differ from the policymaker's subjective weight $\zeta$. The following property characterises the value functions with respect to $\zeta$.

Property 1. For a policymaker with combined mandates, $L_{M P}$ is strictly increasing in $\zeta$ whereas $L_{F S}$ is strictly decreasing in $\zeta$, independently of the instrument used.

This suggests that the loss associated with each objective falls as the weights placed by the policymaker are aligned with those of the social loss function. ${ }^{\text {[2] }}$

The paper compares different institutional settings by examining each shock separately. The loss associated with monetary and macroprudential stability is determined separately by evaluating $L^{j j^{\prime}}$ at $z=0$ and $z=1$, respectively. From the linearity of $L^{j j^{\prime}}$ with respect to $z$, institutional settings that result in a higher loss for both objectives are eliminated as inferior. In what follows, it is considered that aggregate demand is more sensitive to changes in the policy rate than to changes in the lending rate, i.e. $a_{\rho} \leq a_{i}$. The policy rate has a direct effect on macroeconomic outcomes via the interest rate channel, whereas capital requirements influence macroeconomic outcomes indirectly through the credit channel, as changes in banks' balance sheet influence the price of credit, which in turn affects the aggregate demand. As such, the policy rate is considered to be a more effective instrument than capital requirements for macroeconomic policy, as less frictions are involved in the policy transmission.

Finally, in order for the comparisons undertaken between different institutional settings to be tractable without altering the main results, the model's parameters are assumed to satisfy

$$
a_{\rho} \geq\left(\beta+a_{\pi}\right) /(\beta \theta) .
$$

This is a sufficient condition that simplifies the analysis and introduces a lower bound to the sensitivity of output to changes in the price of credit, and consequently to the effectiveness of policy transmission through the credit channel. A discussion on the implications of this assumption is provided in the analysis.

\subsection{Aggregate Demand Shock}

Consider first the case where an aggregate demand shock distorts the economy from the equilibrium. The shock affects inflation and output, which in turn influences the lending rate in the loan market, and therefore the spread between the lending and policy rate.

Lemma 1. For an aggregate demand shock, the policy rate is the dominant instrument for a single policymaker, and a combined mandate is the dominant institutional structure in relation to the complete separation of mandates.

\footnotetext{
${ }^{12}$ From the value function and the first-order conditions, $\partial L_{M P} / \partial \zeta=\left(\partial L_{M P} / \partial i\right)^{2} / \zeta \partial^{2} L / \partial i^{2}>0$ and $\partial L_{F S} / \partial \zeta=-\left(\partial L_{F S} /(\partial i)^{2} /(1-\zeta) \partial^{2} L / \partial i^{2}\right)<0$. The comparative static effect of $\zeta$ remains the same when $k$ is the policymaker's instrument.
} 
Proof. See Appendix

According to Property $\mathbb{W}$, the loss for a single policymaker increases when a greater weight is assigned to the opposing objective, as control over a single instrument does not provide the flexibility to restrain the spillover effect between the two objectives. In the Appendix it is shown that capital requirements results in greater losses for either objective and therefore it constitutes an inferior instrument, independently of the preference parameters $\zeta$ and $z$.

The intuition behind this result is as follows. For $z=0$, both instruments adjust to offset the effect of the shock on aggregate demand and minimise the variability of inflation and output by moving in the same direction. ${ }^{[3]}$ However, the positive relationship between $k$ and $\rho$ as indicated by (B) implies that financial stability will deteriorate further by adjusting $k$ following the shock, whereas the negative relationship between $i$ and $\rho$ through the effect of the former on output implies that financial stability improves by adjusting $i$ instead. ${ }^{\text {प] }}$ Moreover, for $z=$ 1 the instruments move in opposite directions in order to minimise the spread between the two rates. From the inverse relationship between $i$ and $\rho$ it follows that the adjustment of $i$ also improves monetary stability contrary to $k$, which results in greater variability for inflation and output. Hence, policy objectives are conflicting when $k$ is adjusted due to the negative spillovers. Instead, adjustment of $i$ yields a positive spillover effect, establishing the two policy goals as complementary and resulting in a lower social loss. ${ }^{\text {[5 }}$

Moreover, when mandates are separated, the first-best solution is not an equilibrium out-

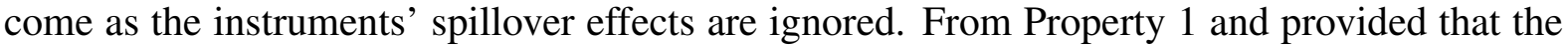
first-best can be attained for extreme values of $\zeta$ when mandates are combined, it is shown in the Appendix that this setting results in a lower aggregate loss for any $\zeta$. In particular, the negative relationship between the two rates implies that the adjustment of $i$ will improve both monetary and financial stability following a shock, regardless of the policymaker's preferences. However, a separate financial regulator does not consider the effect that $k$ has on inflation and output that hinders monetary stability.

The optimal institutional arrangement following an aggregate demand shock is summarised below.

Proposition 1. Following an aggregate demand shock, a unique value of $z$ exists, namely $\bar{z}$, such that the dominant institutional structure is partial separation of mandates for any $z \leq \bar{z}$ and a single policymaker with a combined mandate and control over the short-term interest rates for any $z>\bar{z}$.

\section{Proof. See Appendix}

When monetary stability is more socially valuable, partial separation is the dominant configuration as the monetary policymaker can set the policy rate to achieve the first-best outcome so that $L_{M P}^{R}=L_{M P}\left(i_{f}, k_{f}\right)<L_{M P}^{i}$ for any $\zeta \in(0,1]$, while the dispersion between the two rates implies that $L_{F S}^{R}>L_{F S}\left(i_{f}, k_{f}\right)$. However, as financial stability becomes more socially important for higher values of $z$, the benefit from attaining $L_{M P}\left(i_{f}, k_{f}\right)$ diminishes and the setup of a single policymaker with control over the policy rate becomes the dominant setting.

\footnotetext{
${ }^{13}$ Indeed, $\partial L_{M P} / \partial i=2(\pi+\lambda \beta y) \partial \pi / \partial i<0$ and $\partial L_{M P} / \partial k=2(\pi+\lambda \beta y) \partial \pi / \partial k<0$, as $\partial \pi / \partial i<0$ and $\partial \pi / \partial k<0$ from (B)).

${ }^{14}$ Alternatively, it can be verified that $\partial L_{F S} / \partial k=2 \rho \partial \rho / \partial k>0$ and $\partial L_{F S} / \partial i=-2(\rho-i)(1-\partial \rho / \partial i)<0$ following an aggregate demand shock.

${ }^{15}$ Even though $i$ is the dominant instrument for a wide range of parameters, the assumption $a_{\rho} \leq a_{i}$ is sufficient to guarantee that it remains dominant for the limit case where $\zeta$ tends to zero, i.e. $L_{F S}^{i k}<0$. Relaxing this assumption will only complicate the analysis as $L_{M P}^{i k}<0$ for any $\zeta$ and therefore, from the linearity of social loss function in $z, i$ remains the dominant instrument over a range of $z$ values.
} 
Partial separation's dominance relies on the fact that the spillover effect of $k$ on monetary stability is internalised. In other words, the adjustment in $i$ is sufficiently strong not only to neutralise the opposing effect of $k$ on inflation and output variability, but to achieve the first-best outcome for monetary stability following the shock. As such, it is the dominant institutional structure when $z$ is low, but due to the resulting financial instability, it is dominated by the arrangement with a dual mandate for high values of $z$.

\subsection{Aggregate Supply Shock}

An aggregate supply shock has a permanent effect to the economy as inflation and output move in opposite directions. Policymakers' response depends on inflation aversion which can potentially influence the resulting loss due to the instruments' spillover effects on the policy objectives.

Lemma 2. For an aggregate supply shock and provided that policymakers are inflation-averse, capital requirements is the dominant instrument for a single policymaker, and partial separation is the dominant institutional structure when mandates are separated.

Proof. See Appendix

Following the shock, output and lending rate move in the opposite direction to inflation. A policymaker with a dual mandate can adjust either instrument to reduce inflation variability. However, the inverse relationship between the two rates suggests that financial stability deteriorates further by adjusting $i$, whereas it improves by adjusting $k$ due to the positive relationship between $k$ and $\rho$. When the policy focus is on financial stability instead, the instruments move in opposite directions to reduce the spread between the two rates, which leads to greater variability of inflation and output in terms of $i$, but to an improvement of monetary stability in terms of $k$. As such, the adjustment of $i$ has a negative spillover effect that renders the objectives as conflicting, whereas adjustment of $k$ yields a positive spillover effect. In this case, complementarity of objectives results in a lower loss. Note that, although the policymaker's inflation aversion can influence the direction of instruments' adjustment and therefore the spillover effect on either objective, it does not alter the main result of the above Lemma. ${ }^{[6}$

Moreover, when mandates are separated, it is only partial separation that internalises the spillover effect of $k$ to monetary stability and therefore attains $L_{M P}\left(i_{f}, k_{f}\right)$. In addition, the ensuing effect on the spread between the two rates is shown in the Appendix to be smaller for the same arrangement. Hence, mandate separation without coordination remains the inferior setting for any $z$.

The optimal institutional arrangement is described in the following Proposition.

Proposition 2. Following an aggregate supply shock, a unique value of z exists, namely $\overline{\bar{z}}$, such that the dominant institutional structure is partial separation of mandates for any $z \leq \overline{\bar{z}}$ and a single policymaker with a combined mandate and control over capital requirements for any $z>\overline{\bar{z}}$.

Proof. See Appendix

For the separate configuration, the instruments move in the same direction following the shock, as the macroprudential regulator aims to reduce the spread between the lending and policy rate, while the monetary policymaker, sets $i$ to achieve $L_{M P}\left(i_{f}, k_{f}\right)$ anticipating the effect that $k$ has on inflation. However, due to the inverse relationship between the two rates, the adjustment in

\footnotetext{
${ }^{16}$ As demonstrated in the Appendix, even for an output-averse policymaker, $L_{F S}^{i k} \geq 0$ for any $\zeta$ whereas $L_{M P}^{i k} \geq 0$ only for a limited range of $\zeta$ values. Thus, Lemma $\square$ holds for a wide range of parameters' values.
} 
$i$ compromises the objective of financial stability. For example, recall that a positive aggregate supply shock leads to a rise in $\rho$ due to the positive effect on output, and to a fall in inflation. The policymaker with a dual mandate and the separate macroprudential regulator respond by reducing $k$, which leads to an increase in inflation and a consequent fall in the lending rate, improving both objectives. However, the separate monetary policymaker also reduces $i$ to attain $L_{M P}\left(i_{f}, k_{f}\right)$, but the consequent rise in $\rho$ leads to financial instability. As such, separation of mandates with partial cooperation is the dominant configuration for low values of $z$.

The results on the effects of macroeconomic shocks to different institutional arrangements rely on the sensitivity of aggregate demand to the policy and lending rates. In particular, it is considered that the policy rate is a more effective instrument in influencing macroeconomic outcomes than capital requirements, as the former affects the aggregate demand directly, whereas the latter does so indirectly through its influence on the lending rate. This is captured by requiring $a_{\rho} \leq a_{i}$ since more frictions are expected in policy transmission through the credit channel relative to the interest rate channel. In addition, the lower bound on $a_{\rho}$ introduced in (D) preserves capital requirements' ability to influence macroeconomic outcomes and is a sufficient condition that enables the generalisation of the results obtained for a single policymaker to be independent of $\zeta .^{\square}$ If this condition is violated, the results obtained still hold for a wide range of the model's parameters even for very low values of $a_{\rho}$, as threshold values of $\zeta$ can be defined such that dominance associated with each objective, and therefore the overall results on macroeconomic stability, remain unchanged. Thus, the lower bound on $a_{\rho}$ simplifies the analysis without altering the main conclusions of the model.

\subsection{Financial Shocks}

Financial shocks on either side of the lending market can destabilise the economy by influencing the lending rate.

Proposition 3. Following a financial shock, both partial separation and a combined mandate with control over capital requirements are the dominant institutional structures as they attain the first-best outcome for any $\zeta$.

Regardless of whether the financial shock affects the demand or supply side of the loan market, capital requirements have a direct effect on the market so that its adjustment can counterbalance any effect that the shocks might have on the lending rate. In this case, absence of spillover effects implies that financial stability is maintained while macroeconomic variables remain unaffected. Indeed, as indicated in the social planner's case, only the optimal rule for capital requirements depends on $H$. As such, macroeconomic stability is achieved with a single instrument whereas in the case of partial separation, the monetary policymaker optimally selects not to respond to financial shocks. In contrast, adjustments of the policy rate generate spillover effects as it can only influence the lending market indirectly. Thus, the policy rate cannot pursue both objectives ${ }^{\square]}$ whereas in the case of complete separation, ignoring the prudential regulator's response leads to inferior outcomes.

Overall, financial shocks do not have a major influence in determining the optimal institutional configuration when considering all other types of shocks. In relation to an aggregate supply shock, the dominant setting remains unaffected, whereas in terms of an aggregate demand shock, the dominant setting differs only when monetary stability is socially important.

\footnotetext{
${ }^{17}$ Necessary and sufficient conditions can be derived for all the comparisons performed for a single policymaker as described in the Appendix.

${ }^{18}$ Note that instrument substitutability is maintained, as the first-best outcome can be achieved for extreme values of preferences' parameters.
} 


\section{Dynamic Setting}

The model developed in the previous section is extended in a dynamic framework with discrete time as in Svensson (1997, 1999) and summarised below

$$
\begin{aligned}
& y_{t+1}=a_{y} y_{t}-a_{i}\left(i_{t}-E_{t}\left[\pi_{t+1}\right]\right)-a_{\rho}\left(\rho_{t}-E_{t}\left[\pi_{t+1}\right]\right)+h_{t+1} \\
& \pi_{t+1}=\pi_{t}+\beta y_{t}+\epsilon_{t+1} \\
& \ell_{t}^{d}=-\ell_{\rho}\left(\rho_{t}-E_{t}\left[\pi_{t+1}\right]\right)+\ell_{y} y_{t}+\eta_{t} \\
& \ell_{t}^{s}=c y_{t}-k_{t}+e_{t} \\
& \ell_{t}^{d}=\ell_{t}^{s} .
\end{aligned}
$$

All parameters and variables are defined as before and $E_{t}$ denotes expectations conditional upon the information available at time period $t$, so that $E_{t}\left[\pi_{t+1}\right]$ is the expected next period's inflation. In each period, market clearing in the loan market determines the equilibrium lending rate and the demand for loans is considered to be more sensitive to changes in the output gap than the supply. The aggregate supply in the model is described by the accelerationist Phillips curve so that the change in inflation is increasing in the lagged output gap. The aggregate demand indicates that output gap is serially correlated and decreasing in the real loan rate and policy rate. As before, shocks are represented by white noise variables $h, \epsilon, \eta$ and $e$ which are uncorrelated with variances $\sigma_{h}^{2}, \sigma_{\epsilon}^{2}, \sigma_{\eta}^{2}$ and $\sigma_{e}^{2}$, respectively.

The timing of events considered within each time period is as follows. Initially, having observed the past period's values of the macroeconomic variables, policymakers set the instrument under control. Subsequently, shocks are realised and the current period's lending rate, inflation and output gap are determined. Note that an important feature of the model is that policy instruments affect inflation with a longer lag than the output gap. Indeed, changes in either instrument affect next period's output, which in turn influences the following period's inflation.

The analysis begins with the derivation of the first-best solution which acts as a benchmark in the evaluation of alternative institutional configurations. Although a policymaker engaged in stabilisation policy has the same loss function in each period as in the static framework, the objective function in the dynamic context is the discounted sum of the expected future losses. For the unconstrained case with two objectives and two instruments, a social planner solves the following optimisation problem at time period $t$.

\section{General Optimisation Problem (Dynamic).}

$$
\begin{aligned}
& \min _{\left\{i_{t+j}, k_{t+j}\right\}_{j=0}^{\infty}} z E_{t} \sum_{j=0}^{\infty} \delta^{t+j} L_{t+j, F S}+(1-z) E_{t} \sum_{j=1}^{\infty} \delta^{t+j} L_{t+j, M P} \\
& \text { subject to } L_{t+j, F S}=\left(\rho_{t+j}-i_{t+j}\right)^{2}, L_{t+j, M P}=\pi_{t+j}^{2}+\lambda y_{t+j}^{2} \\
& \text { and the constraints (प0) to (ष), }
\end{aligned}
$$

where $\delta \in(0,1)$ is the discount factor. In terms of monetary stability, instruments set at time period $t$ affect next period's monetary variables, and therefore the objective function incorporates losses starting from period $t+1$. In terms of financial stability, losses are considered starting from the same time period $t$ as the policy and equilibrium lending rates are determined within the same time period.

To simplify the analysis in deriving the first-best solution, the optimisation problem for each objective is considered separately and without imposing any restrictions on the instruments available. Similar to the static case, the linearity of the aggregate social loss function in 
$z$ implies the optimal rule for each instrument is independent of $z$ and consequently the social loss value function is linear in $z$. Hence, focusing on the optimisation problem for each objective simplifies the analysis in deriving the optimal rules and determining the associated value functions that facilitate the comparison of different institutional settings.

The optimal policy rules are derived by solving the resulting dynamic optimisation problem.

Corollary 1. Instrument substitutability is maintained in the dynamic framework with discrete time, as either instrument can attain the same value function for each objective. The first-best solution $\left(i_{t}^{*}, k_{t}^{*}\right)$ satisfies the following system of equations

$$
\begin{aligned}
& \phi y_{t}-a_{i}\left(i_{t}-\pi_{t}\right)-a_{\rho} k_{t} / \ell_{\rho}=-v \beta \delta\left(\pi_{t}+\beta y_{t}\right) /\left(\lambda+v \beta^{2} \delta\right) \\
& k_{t} / \ell_{\rho}=i_{t}-\pi_{t}-y_{t}(\beta+\theta),
\end{aligned}
$$

where $\phi=a_{y}+a_{i} \beta-a_{\rho} \theta$ to simplify the notation and $v$ is a function of the model's parameters defined in the Appendix.

Proof. See Appendix

Solving the Bellman equations for each objective, given the inflation and output gap transition functions as shown in the Appendix, yields the above first-order conditions which remain the same independently of the chosen instrument such that instrument substitutability is maintained in the dynamic setting.

Given the optimal policy rules, the corresponding value functions are

$$
\begin{aligned}
& L_{M P}(\pi, y)=\delta v\left((\pi+\beta y)^{2}+\frac{\delta}{1-\delta}\left(\sigma_{\epsilon}^{2}+\beta^{2}\left(\sigma_{h}^{2}+a_{\rho}^{2} \sigma_{H}^{2}\right)\right)\right)+\frac{\delta\left(\sigma_{\epsilon}^{2}+\lambda\left(\sigma_{h}^{2}+a_{\rho}^{2} \sigma_{H}^{2}\right)\right)}{1-\delta}, \\
& L_{F S}(\pi, y)=\frac{\sigma_{H}^{2}}{1-\delta}
\end{aligned}
$$

whereas the aggregate value function is a linear transformation of the above expressions. Similarly to the static setting, we define $H_{t}=\left(\eta_{t}-e_{t}\right) / \ell_{\rho}$ and $\sigma_{H}^{2}$ its variance.

Moreover, the conditions on the model's parameters that ensure the stationarity of the state variables for each case under consideration are summarised below.

Corollary 2. For any institutional setting $j$, when the output gap transition function is given by

$$
y_{t+1}^{j}=q^{j}\left(\pi_{t}+\beta y_{t}\right)+g^{j} y_{t}+h_{t+1}-a_{\rho} H_{t},
$$

stationarity of the state variables requires $q^{j}<0$ and $2\left(1+g^{j}\right)+q^{j} \beta>0$, where $q^{j}$ and $g^{j}$ are functions of the model's parameters and depend on the policy rules adopted in setting $j$.

Provided that the inflation transition function is given by the Phillips curve in (Q), the characteristic equation for any setting $j$ has the form $\gamma^{2}-\gamma\left(1+g^{j}+q^{j} \beta\right)+g^{j}=0$. The conditions on $q^{j}$ and $g^{j}$ guarantee that the resulting eigenvalues $\gamma_{1}$ and $\gamma_{2}$ have an absolute value less than one to ensure convergence.

For the first-best outcome, Corollary $\mathbb{W}$ suggests that the output gap transition function remains the same regardless of the instrument used in pursuing either objective and therefore it can be obtained by applying either $i^{*}$ or $k^{*}$ into aggregate demand, which yields

$$
y_{t+1}=-v \beta \delta\left(\pi_{t}+\beta y_{t}\right) /\left(\lambda+v \beta^{2} \delta\right)+h_{t+1}-a_{\rho} H_{t} .
$$

In this case, $g^{*}=0$ and $q^{*}=-v \beta \delta /\left(\lambda+v \beta^{2} \delta\right)$ so that inflation and the output gap are stationary according to Corollary $\square$ as $-1<q^{*} \beta<0$. 


\section{Policy Evaluation in the Dynamic Setting}

When mandates are combined, similar to the static case, the corresponding policy rules and associated value functions depend on $\zeta$. However, as the objective function of the single policymaker is linear in $\zeta$, while the constraints are linear in the state variables and independent of $\zeta$, the value function for each objective is monotonic in $\zeta$. Hence, focusing on each objective in comparing the value function for different instruments and provided that the same outcome is attained for extreme values of $\zeta$, monotonicity implies that dominance remains the same for any $\zeta \in(0,1)$. As such, inferior settings are identified in the following Lemma when dominated for extreme values of social preferences.

Lemma 3. In the dynamic framework and independently of the macroeconomic shock, the policy rate is the dominant instrument for a single policymaker, and partial separation is the dominant institutional setting when mandates are separated.

Proof. See Appendix

The policy rule for a single policymaker when $\zeta=0$ is given by (114), the output gap transition function is described by (II7) regardless of the instrument used. The value functions are shown in the Appendix to have the same form for $z=1$, so that conclusions are drawn by direct comparison of the loss in the initial period. In contrast, when $\zeta=1$ the policy rule for either instrument is given by (15) whereas the output gap transition functions are

$$
\begin{aligned}
& y_{t+1}^{i}=y_{t}^{i}\left(a_{y}-\theta\left(a_{i}+a_{\rho}\right)\right)+h_{t+1}-a_{\rho} H_{t} \\
& y_{t+1}^{k}=\left(a_{i}+a_{\rho}\right)\left(\pi_{t}^{k}+\beta y_{t}^{k}\right)+a_{y} y_{t}^{k}+h_{t+1}-a_{\rho} H_{t} .
\end{aligned}
$$

Since the time path of state variables differs in the two settings, the method of undetermined coefficients is employed to derive the value functions when $z=0$. As discussed in the Appendix, the value functions have the same form in each setting, so that direct comparisons of the coefficients obtained for each instrument enable us to conclude about the overall performance of each instrument. ${ }^{\text {प1 }}$

The above expressions indicate that only $y_{t+1}^{k}$ depends on the lagged inflation as capital requirements affect the real lending rate. In order to minimise the loss from financial instability in each period, the policymaker sets the nominal policy rate equal to the nominal lending rate so that their real values are also equal. Given that the aggregate demand depends only on the real values of the two rates and the real lending rate is determined in the lending market, this implies that the aggregate demand is independent of the inflation. In contrast, changes in capital requirements affect the real lending rate, and therefore by pursuing the objective of financial stability and equalising the nominal values of the two rates, results in $y_{t+1}^{k}$ being dependent on $\pi_{t}$.

The sensitivity of aggregate demand on the two rates has important implications on the performance of each instrument. In particular, although all parameters are considered to be positive, it is interesting to note that when aggregate demand is identically influenced by the two rates but the direction of the effect differs, the choice of the instrument becomes irrelevant. ${ }^{[0]}$ In this case, aggregate demand depends on the spread between the two rates so that,

\footnotetext{
${ }^{19}$ When the policy instrument is $k$ and $z=0$, state variables are stationary for $\zeta=0$ but non-stationary for $\zeta=1$ as $q^{k}=a_{i}+a_{\rho}>0$, which violates the condition introduced in Corollary $\unrhd$. However, as the policy rule and consequently the output gap transition function depends on $\zeta$, stationarity conditions alone cannot be used to make inferences in comparing the two instruments.

${ }^{20}$ This represents a special scenario as all parameters are assumed to be positive.
} 
from the policy objective functions, instruments need to move in opposing directions to promote financial stability in the same period or monetary stability the next period. As such, the instruments' spillover effects become equivalent and consequently the choice of instrument has no effect on aggregate loss. Moreover, in the extreme case where aggregate demand is independent of $k$ so that $a_{\rho}$ is zero, $k$ is not the optimal instrument when the society's preferences are such that a greater emphasis is placed on monetary stability. In contrast, when financial stability is socially valuable, the aggregate demand is insulated against the adverse effects of $k$ adjustments and the negative spillover effect on monetary stability is eliminated. However, as it is shown in the Appendix, as long as there are more frictions involved in policy transmission through $k, i$ remains the dominant instrument.

Moreover, for institutional arrangements where mandates are assigned to different policymakers, evaluation is focusing on financial stability, as partial separation dominates in terms of monetary stability. Specifically, the capital requirements' rule for either setting can be derived from (15) by requiring $i_{t}$ to be zero. In the case where policymakers move sequentially, the interest rate rule is described by (114) where $k_{t}$ is given by the capital requirements rule, while $k_{t}$ is set to zero in the absence of coordination so that

$$
\begin{aligned}
& i_{t}^{R}=\left(\frac{a_{\rho}+M}{a_{i}}+1\right)\left(\pi_{t}+\beta y_{t}\right)+\left(\frac{a_{y}}{a_{i}}\right) y_{t} \\
& i_{t}^{S}=\left(\frac{M}{a_{i}}+1\right)\left(\pi_{t}+\beta y_{t}\right)+\left(\frac{a_{y}-a_{\rho} \theta}{a_{i}}\right) y_{t},
\end{aligned}
$$

where $M=v \beta \delta /\left(\lambda+v \beta^{2} \delta\right)>0$ to simplify notation. The corresponding output gap transition functions are given by ([17) and

$$
y_{t+1}^{S}=-\left(M-a_{\rho}\right)\left(\pi_{t}+\beta y_{t}\right)+a_{\rho} \theta y_{t}+h_{t+1}-a_{\rho} H_{t} .
$$

Provided that the transition functions differ in the two settings, policy performance can be assessed by comparing the corresponding value functions, as demonstrated in the Appendix. However, unlike the case of a single policymaker, such comparison is computationally cumbersome without providing any conclusive result as it depends on the model's parameters.

Nevertheless, interesting insights about the effect of different parameters can be derived by examining the policy rules in each case. In particular, as the capital rule is the same in both settings, the resulting loss due to financial instability depends on the time path of the policy rate. Starting from some initial values for inflation and output gap, when the future is heavily discounted, the value function in each case is equal to the corresponding interest-rate rule as described by (20) and (2I). Clearly, direct comparison of the two expressions indicates that the loss is greater under partial separation for any $a_{\rho}<a_{i}$. By taking into account the choice of $k$ when setting $i$, the interest-rate rule is more responsive to changes in inflation and output gap. This leads to greater volatility in the policy rate in comparison to the case of complete separation, which has a detrimental effect on financial stability.

In contrast, for a high rate of time preferences, it is shown in the Appendix that the comparison between the value functions in the two cases does not only depend on the sensitivity of the interest-rate rule to the state variables, but it also depends on the volatility of the state variables which follow different time-paths. Indeed, the adjustment of $i_{t}^{R}$ is sufficiently large so that the state variables follow the same time-path as in the case of full coordination. The resulting lower inflation volatility imposes a lower cost on the value function in relation to the case of complete separation. Dominance of partial separation in terms of financial stability depends on whether the lower inflation volatility outweighs the greater responsiveness of $i_{t}^{R}$ to 
changes in state variables, which in turn depends on the parameters of the model. In particular, it is shown that when the demand and supply for loans have the same sensitivity to changes in output gap, partial separation is the dominant setting for high values of $a_{\rho}$, as inflation volatility has a strong impact on the aggregate loss. This effect is reinforced for high values of inflation aversion and low values of the sensitivity of inflation to lagged output gap. Overall, when both policy objectives are considered together, partial separation is the dominant setting for a wide range of the model's parameters, as it attains the first-best outcome for monetary stability.

Having identified the inferior configurations, the Proposition below summarises our findings.

Proposition 4. A unique value of z exists, namely $\widetilde{z}$, such that the dominant institutional structure is partial separation of mandates for any $z \leq \widetilde{z}$ and a single policymaker with a combined mandate and control over the policy rate for any $\widetilde{z}<z$, provided that the model's parameters are such that inflation and output gap are stationary.

Since partial separation always dominates for $z=0$ and the single policymaker attains the first-best for $z=\zeta=1$, to prove the existence of $\widetilde{z}$ it is sufficient to show that the latter is the optimal configuration for $\zeta=0$. In this case the two settings share the same output gap transition equation and the value function has the same form. As such, from a simple comparison of the loss functions at the initial period, it can be shown that a dual mandate is the optimal setting independently of $\zeta$, provided that inflation and the output gap are stationary, which imposes restrictions on the model's parameters as specified by Corollary 2].

Evidently, coordination plays a crucial role in the optimal design of policymaking. Establishing an independent macroprudential regulator could enhance accountability and reinforce the commitment in the pursuit of policy objectives, but coordination failures yield inferior outcomes. This issue has been acknowledged in recent regulatory reforms and addressed by promoting information exchange between different institutions or committees. For example, the Governors of the Bank of England and European Central Bank are chairing both the monetary and financial policy committees (i.e., the Financial Policy Committee and the General Board of European Systemic Risk Board, respectively). ${ }^{[2}$ Although concurrent policy adjustments are uncommon, sharing of costly information provides policymakers with more accurate knowledge of each others' reaction function that leads to superior outcomes. As such, the ongoing institutional reforms towards banking integration in the Euro-area aim to enhance macroeconomic stability in relation to the segregated financial system that was in place in the wake of recent financial crisis. Harmonisation of prudential policy rules, greater transparency and information sharing intend to reinforce policymakers' coordination. However, the shock-absorbing capacity of a centralised institutional configuration and the role of domestic prudential regulators and fiscal authorities to avert financial fragility and resolve bank insolvencies are crucial to the establishment of a banking union (Belke and Gros 2016).

\footnotetext{
${ }^{21}$ From transition equation (파) it follows that $q^{i}=0$ and $g^{i}=a_{y}-\theta\left(a_{i}+a_{\rho}\right)$. Since $y_{t+1}^{i}$ is independent of $\pi$, the condition $q^{j}<0$ is violated. However, the presence of a unit root is only due to the assumed form of the Phillips curve described in (QI) as stationarity is guaranteed when the sensitivity of inflation to its lagged value is considered to be less than one. The introduction of a new parameter does not affect the results obtained and will only add to the complexity of the analysis.

${ }^{22}$ Following the Dodd-Frank Act (2010) in the US, the Chairman of the Board of Governors of the Fed is a voting member of the Financial Stability Oversight Council, while the Office for Financial Research is established to collect and publicise financial data.
} 


\section{Conclusions}

The paper evaluates the performance of different institutional configurations in the everchanging landscape of policymaking by examining the interaction of monetary and macroprudential policies, and the spillovers that instruments have on policymakers' objectives. Separation of the mandates without coordination between policymakers is an inferior arrangement regardless of the type of shock, whereas partial separation becomes the optimal arrangement when monetary stability is more socially important. By rationally inferring the consequences of macroprudential regulator's actions on output and inflation, the monetary policymaker can optimally set the policy rate. In contrast, when financial stability is more socially desirable, the arrangement with combined mandates becomes the dominant setting as the spillover effects of the policy rate on financial stability are internalised. In the static version of the model, the selection of the optimal instrument depends on the type of shock that affects the economy, whereas in the dynamic setting, capital requirements is inferior instrument as it results in greater volatility of macroeconomic variables.

However, this finding does not dismiss the need for policy coordination and information sharing. Indeed, at least from a theoretical perspective, it can be shown that a macroprudential regulator with a second-mover advantage that takes into account the effects of monetary policy on financial variables of interest is the dominant arrangement when financial stability is socially important. Although this setting can be compared against alternative arrangements developed in the paper, it is not representative of the social preferences, as monetary stability considerations receive greater importance on the ordinary operations by policymakers.

In addition, it is noteworthy that the results obtained are independent of persistence that could be exhibited by the shocks considered. Specifically, when shocks follow a stationary autoregressive process (of any order), and provided that shocks of different types are uncorrelated, it is only their variances that are influenced. Hence, the value functions of the corresponding configurations are perturbed in a symmetric way so that comparisons between them remain unaffected.

The simple framework developed in the paper examines the interaction of macroeconomic policies and demonstrates in a tractable manner that the optimal policy design depends on a variety of factors which explains the wide range of results in the literature. Apart from the policymakers' and society's preferences over the policy goals, some assumptions of the model, such as the degree of monetary policymaker's inflation-aversion as well as parameter values that determine the sensitivities of the policy objectives to the two instruments, have an important role to play in the suggested policy recommendations as it has been highlighted in the analysis. In addition, the characteristics of the model that establish instruments' substitutability are also crucial. The first-order conditions indicate that the minimum loss associated with either objective is independent of the instrument used. Thus, the comparisons between different configurations are simplified as the first-best outcome is independent of social preferences over the two objectives and therefore it could be attained by policymakers. Violation of this property will result in optimal rules becoming dependent on social preferences that will prevent the first-best outcome to act as benchmark and aggravate the complexity in evaluating alternative settings. ${ }^{[3]}$ Extending the model to an open economy and consider the role of fiscal policy in examining policy interactions in a micro-founded framework, but without compromising

\footnotetext{
${ }^{23}$ For example, introduction of alternative specifications of policymakers' loss function such as the linex specification which captures policymakers' asymmetric preferences regarding the direction of movement of policy variables from their targeted values (see Surico 2007) or non-linearities of Phillips curves supported by empirical findings (see Doser et al, 2018).
} 
the tractability of the policy spillovers, are some important concerns that are planned to be addressed in future work.

\section{Acknowledgments}

We would like to acknowledge the participants in $12^{\text {th }}$ Infinity Conference (Prato), $5^{\text {th }}$ Word Finance Conference (Venice), $14^{\text {th }}$ Infinity Conference (Dublin) and Royal Economic Society 2016 Annual Conference (Sussex) for the useful comments and stimulating discussions.

\section{References}

\section{References}

Aiyar, S., C. W. Calomiris, and T. Wieladek (2014). Does macro-prudential regulation leak? Evidence from a UK policy experiment. Journal of Money, Credit and Banking 46(s1), 181 -214 .

Aiyar, S., C. W. Calomiris, and T. Wieladek (2016). How does credit supply respond to monetary policy and bank minimum capital requirements? European Economic Review 82, 142 165.

Altunbas, Y., L. Gambacorta, and D. Marqués-Ibanez (2014). Does monetary policy affect bank risk? International Journal of Central Banking, 95 - 135.

Angelini, P., S. Neri, and F. Panetta (2012). Monetary and macroprudential policies. Working Paper Series 1449, European Central Bank.

Angelini, P., S. Neri, and F. Panetta (2014). The interaction between capital requirements and monetary policy. Journal of Money, Credit and Banking 46(6), 1073 - 1112.

Angeloni, I. and E. Faia (2013). Capital regulation and monetary policy with fragile banks. Journal of Monetary Economics 60, 311 - 324.

Arellano, C., A. Atkeson, and M. Wright (2016). External and public debt crises. NBER Macroeconomics Annual 30(1), 191 - 244.

Beau, D., L. Clerc, and D. Klingebiel (2012). Macro-prudential policy and the conduct of monetary policy. Working Paper 8, Banque de France.

Belke, A. and D. Gros (2016). On the shock-absorbing properties of a banking union: Europe compared with the United States. Comparative Economic Studies 58(3), 359-386.

Bernanke, B. S. and A. S. Blinder (1988). Credit, money, and aggregate demand. American Economic Review 78(2), 435 - 439.

Bernanke, B. S. and M. Gertler (1995). Inside the black box: The credit channel of monetary policy transmission. Journal of Economic Perspectives 9(4), 27 - 48.

Borio, C. and H. Zhu (2012). Capital regulation, risk-taking and monetary policy: A missing link in the transmission mechanism? Journal of Financial Stability 8(4), 236 - 251. 
Bridges, J., D. Gregory, M. Nielsen, S. Pezzini, A. Radia, and M. Spaltro (2014). The impact of capital requirements on bank lending. Working Paper 486, Bank of England.

Cecchetti, S. G. and M. Kohler (2014). When capital adequacy and interest rate policy are substitutes (and when they are not). International Journal of Central Banking 10, 205 - 231.

Cecchetti, S. G. and L. Li (2008). Do capital adequacy requirements matter for monetary policy? Economic Inquiry 46(4), 643 - 659.

Ciccarelli, M., A. Maddaloni, and J.-L. Peydró (2015). Trusting the bankers: A new look at the credit channel of monetary policy. Review of Economic Dynamics 18(4), 979 - 1002.

Collard, F., H. Dellas, B. Diba, and O. Loisel (2017). Optimal monetary and prudential policies. American Economic Journal: Macroeconomics 9(1), 40 - 87.

Copelovitch, M. S. and D. A. Singer (2008). Financial regulation, monetary policy, and inflation in the industrialized world. The Journal of Politics 70(3), $663-680$.

Curdia, V. and M. Woodford (2010). Credit spreads and monetary policy. Journal of Money, Credit and Banking 42, 3 - 35 .

Debortoli, D., J. Kim, J. Lindé, and R. Nunes (2017). Designing a simple loss function for central banks: Does a dual mandate make sense? Working Paper 17/164, IMF.

DiNoia, C. and G. DiGiorgio (1999). Should banking supervision and monetary policy tasks be given to different agencies? International Finance 2(3), $361-378$.

Doser, A., R. Nunes, N. Rao, and V. Sheremirov (2018). Inflation expectations and nonlinerities in the Phillips Curve. Working Paper DP 10/18, University of Surrey.

Doumpos, M., C. Gaganis, and F. Pasiouras (2015). Central bank independence, financial supervision structure and bank soundness: An empirical analysis around the crisis. Journal of Banking \& Finance 61(S1), S69-S83.

Galati, G. and R. Moessner (2013). Macroprudential policy - A literature review. Journal of Economic Surveys 27, 846-878.

Gelain, P. and P. Ilbas (2017). Monetary and macroprudential policies in an estimated model with financial intermediation. Journal of Economic Dynamics and Control (78), 164 - 189.

Goodhart, C. and D. Schoenmaker (1993). Institutional separation between supervisory and monetary agencies. Working Paper 52, London School of Economics.

Goodhart, C. and D. Schoenmaker (1995). Should functions of monetary policy and banking supervision be separated? Oxford Economic Papers 47(4), 539 - 560.

Ioannidou, V. (2005). Does monetary policy affect the central banks role in bank supervision? Journal of Financial Intermediation 14(1), 58 - 85.

Kahou, M. E. and A. Lehar (2017). Macroprudential policy: A review. Journal of Financial Stability 29, $92-105$.

Lima, D., I. Lazopoulos, and V. Gabriel (2016). The effect of financial regulation mandate on inflation bias: A dynamic panel approach. Working Paper DP 06/16, University of Surrey. 
Neuenkirch, M. and M. Nöckel (2018). The risk-taking channel of monetary policy transmission in the euro area. Journal of Banking and Finance 93, 71-91.

Peek, J., E. S. Rosengren, and G. M. B. Tootell (1999). Is bank supervision central to central banking? The Quarterly Journal of Economics 114(2), 629 - 653.

Pellegrina, L. D., D. Masciandaro, and R. Pansini (2013). The central banker as prudential supervisor: Does independence matter? Journal of Financial Stability 9(3), 415 - 427.

Rubio, M. and J. A. Carrasco-Gallego (2014). Macroprudential and monetary policies: Implications for financial stability and welfare. Journal of Banking and Finance 49, 326 336.

Surico, P. (2007). The Fed's monetary policy rule and U.S. inflation: The case of asymmetric preferences. Journal of Economic Dynamics and Control 31(1), 305 - 324.

Svensson, L. (1997). Inflation forecast targeting: Implementing and monitoring inflation targets. European Economic Review 41(6), 1111 - 1146.

Svensson, L. (1999). Inflation targeting: Some extensions. Scandinavian Journal of Economics 101(3), $337-361$.

Tayler, W. J. and R. Zilberman (2016). Macroprudential regulation, credit spreads and the role of monetary policy. Journal of Financial Stability 26, $144-158$.

Taylor, J. B. and J. C. Williams (2009). A black swan in the money market. American Economic Journal: Macroeconomics 1(1), 58-83.

Valencia, F. (2014). Monetary policy, bank leverage, and financial stability. Journal of Economic Dynamics and Control 47, 20 - 38.

Van den Heuvel, S. (2002). Does bank capital matter for monetary transmission? Economic Policy Review 8(1), 259 - 265.

Vickers, J. (2002). The hedgehog and the fox in economic policy. Oxford Business Alumni Lecture.

Woodford, M. (2003). Interest and Prices. Princeton University Press.

Woodford, M. (2012). Inflation targeting and financial stability. Working Paper 17967, NBER.

\section{A. Appendix}

\section{Proof of Lemma $\mathrm{Z}$}

From the linearity of $L^{j j^{\prime}}$ in $z$, a sufficient condition for an institutional structure to dominate is to attain the lowest loss in terms of both policy objectives following a shock. The optimal policy rules for a single policymaker are determined by (B) and either first-order condition $\Phi_{i}(i, 0 ; \zeta)$ or $\Phi_{k}(0, k ; \zeta)$ depending on the instrument, where $h=1, \epsilon=0$ and $H=0$. 
Note that $L_{M P}^{i k}(\zeta=0)=0$ and $L_{F S}^{i k}(\zeta=1)=0$ as the policymaker attains the first-best outcome independently of the instrument, whereas

$L_{M P}^{i k}(\zeta=1)=\left(1+\lambda \beta^{2}\right)\left(\frac{1}{\left(r+\beta \theta a_{i}\right)^{2}}-\frac{1}{\left(r-\beta \theta a_{\rho}\right)^{2}}\right)<0$ and $L_{F S}^{i k}(\zeta=0)=\frac{1}{a_{i}^{2}}-\frac{1}{a_{\rho}^{2}} \leq 0$

since $a_{\rho} \leq a_{i}$ so that $L_{M P}^{i k}(\zeta) \leq 0$ and $L_{F S}^{i k}(\zeta) \leq 0$ from Property $\mathbb{\square}$. Hence, $L^{i k}(\zeta) \leq 0$ for any $\zeta$ and $z$.

Since a policymaker with dual mandate attains the first-best for $z=\zeta=0$ and $z=\zeta=1$, note that

$$
\begin{aligned}
& L_{M P}^{i S}(\zeta=1)=\left(1+\lambda \beta^{2}\right)\left(\left(\frac{1}{r+\beta \theta a_{i}}\right)^{2}-\left(\frac{\beta \theta a_{\rho}}{r\left(r-\beta \theta a_{\rho}\right)}\right)^{2}\right) \text { and } \\
& L_{F S}^{i S}(\zeta=0)=-\frac{\beta \theta\left(2 r+\beta \theta a_{i}\right)}{r^{2} a_{i}}<0 .
\end{aligned}
$$

Therefore, $L_{F S}^{i S}<0$ from Property $\mathbb{W}$ while the condition in (प) is sufficient to ensure $L_{M P}^{i S}<0$ for any $\zeta$. Hence, $L^{i S} \leq 0$ for any $\zeta$ and $z$.

\section{Proof of Proposition $\square$}

To prove existence of $\bar{z}$ it is sufficient to show that $L_{F S}^{i R}<0$ since $L_{M P}^{i R}>0$ as $L_{M P}^{R}=$ $L_{M P}\left(i_{f}, k_{f}\right)$. Since

$$
L_{F S}^{i R}(\zeta=0)=-\frac{\beta \theta\left(a_{i}+a_{\rho}\right)\left(\beta+\beta \theta a_{i}+a_{\pi}+r\right)}{a_{i}\left(\beta+a_{\pi}\right)^{2}}<0
$$

then $L_{F S}^{i R}<0$ for any $\zeta$ from Property $\mathbb{1}$. Hence, linearity of $L^{i R}$ in $z$ implies that a unique value $\bar{z}$ exists such that $L^{i R}>0$ for $z \in(0, \bar{z})$ and $L^{i R}<0$ for $z \in(\bar{z}, 1)$.

\section{Proof of Lemma 2}

Similar to the proof of Lemma प, considering extreme values for the preference parameters, $L_{M P}^{i k}(\zeta=0)=0$ and $L_{F S}^{i k}(\zeta=1)=0$ whereas

$$
\begin{aligned}
& L_{M P}^{i k}(\zeta=1)=\frac{\theta a_{\pi}\left(a_{i}+a_{\rho}\right)}{\left(\beta+a_{\pi}\right)^{2}\left(r+\beta \theta a_{i}\right)^{2}}\left(2\left(\beta+a_{\pi}\right)\left(1-\lambda \beta a_{\pi}\right)+\theta\left(a_{i}+a_{\rho}\right)\left(2 \beta+a_{\pi}\left(1-\lambda \beta^{2}\right)\right)\right), \\
& L_{F S}^{i k}(\zeta=0)=\frac{\left(a_{i}+a_{\rho}\right)\left(1+\theta a_{\rho}-\lambda \beta a_{\pi}\right)}{\left(1+\lambda \beta^{2}\right) a_{i}^{2} a_{\rho}^{2}}\left(\theta a_{\rho}\left(a_{i}+a_{\rho}\right)-\left(a_{i}-a_{\rho}\right)\left(1-\lambda \beta a_{\pi}\right)\right) .
\end{aligned}
$$

Note that $L_{M P}^{i k}(\zeta=1)>0$ since $\lambda \beta a_{\pi}<1$. Similarly, the condition in (D) guarantees that $a_{\rho}>\left(1-a_{\pi} \lambda \beta\right) / \theta$ so that $L_{F S}^{i k}(\zeta=0)>0$ and therefore, from Property $\mathbb{U}, L_{F S}^{i k}>0$ for any $\zeta$ and $z$.

Moreover, partial separation dominates for $z=0$ as $L_{M P}^{R}=L_{M P}\left(i_{f}, k_{f}\right)$ and

$$
L_{F S}^{S R}=\frac{\theta a_{\pi} a_{\rho}}{1+\lambda \beta^{2}}\left(\frac{r+\theta \beta a_{i}}{r a_{i}\left(\beta+a_{\pi}\right)}\right)^{2}\left(2\left(\beta+a_{\pi}\right)\left(1-\lambda \beta a_{\pi}\right)+\theta a_{\rho}\left(2 \beta+a_{\pi}\left(1-\lambda \beta^{2}\right)\right)\right)>0,
$$

as $1-\lambda \beta^{2}>0$ for an inflation-averse policymaker, and therefore $L^{S R}>0$ for any $z$. 


\section{Proof of Proposition $\square$}

Similar to Proposition I, to prove the existence of $\overline{\bar{z}}$ it is sufficient to show that $L_{F S}^{k R}<0$ where

$L_{F S}^{k R}(\zeta=0)=r\left(a_{i}+a_{\rho}\right)\left(\frac{1-\lambda \beta a_{\pi}}{\left(1+\lambda \beta^{2}\right) a_{i} a_{\rho}\left(\beta+a_{\pi}\right)}\right)^{2}\left(\left(a_{i}-a_{\rho}\right)\left(\beta+a_{\pi}\right)-\beta \theta a_{\rho}\left(a_{i}+a_{\rho}\right)\right)<0$,

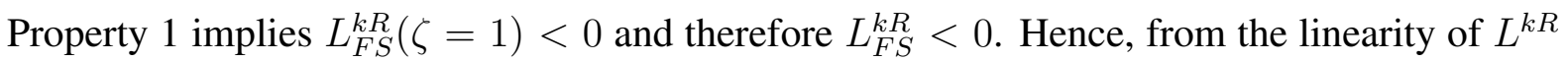
in $z$, a unique value $\overline{\bar{z}}$ exists such that $L^{k R}>0$ for $z \in(0, \overline{\bar{z}})$ and $L^{k R}<0$ for $z \in(\overline{\bar{z}}, 1)$.

\section{Proof of Corollary $\square$}

Consider the optimisation problem in (II3) for a policymaker that sets $i_{t}$ when $z=0$. Given the recursive nature of the problem, as the choice of the control variable affects the next period's values of the state variables described by the transition functions, the multi-period problem is collapsed into a sequence of two period problems. Let $L_{M P}(\pi, y)$ be the value function at $t$. Since $i_{t}$ affects $y_{t+1}$, the Bellman equation is

$$
\begin{aligned}
L_{M P}(\pi, y) & =\min _{i_{t}, y_{t+1}}\left\{E_{t}\left[\left(\pi_{t+1}\right)^{2}+\lambda\left(\phi y_{t}-a_{i}\left(i_{t}-\pi_{t}\right)-a_{\rho} k_{t} / \ell_{\rho}+h_{t+1}\right)^{2}+\delta L_{M P}\left(\pi_{t+1}, y_{t+1}\right)\right]\right\} \\
\text { s.t. } y_{t+1} & =\phi y_{t}-a_{i}\left(i_{t}-\pi_{t}\right)-a_{\rho} k_{t} / \ell_{\rho}+h_{t+1}-a_{\rho} H_{t} \text { and } \pi_{t+1}=\pi_{t}+\beta y_{t}+\epsilon_{t+1} .
\end{aligned}
$$

As $L_{M P}(\pi, y)$ converges to the true value function through successive iterations, we guess that the latter takes the form $L_{M P}(\pi, y)=\mu+v(\pi+\beta y)^{2}$ and check whether this is verified, where $\mu$ and $v$ are the non-negative undetermined coefficients. Solving the optimisation problem we derive the first-order condition

$$
\phi y_{t}-a_{i}\left(i_{t}-\pi_{t}\right)-a_{\rho} k_{t} / \ell_{\rho}=-\delta \beta v\left(\pi_{t}+\beta y_{t}\right) /\left(\lambda+\delta \beta^{2} v\right)
$$

so that the Bellman equation yields

$$
\begin{aligned}
L_{M P}(\pi, y)= & \sigma_{\epsilon}^{2}+\lambda\left(\sigma_{h}^{2}+a_{\rho}^{2} \sigma_{H}^{2}\right)+\delta\left(\mu+v\left(\sigma_{\epsilon}^{2}+\beta^{2}\left(\sigma_{h}^{2}+a_{\rho}^{2} \sigma_{H}^{2}\right)\right)\right) \\
& +\left(\pi_{t}+\beta y_{t}\right)^{2}\left(1+\lambda\left(\frac{\delta \beta v}{\lambda+\delta \beta^{2} v}\right)+\delta v\left(\frac{\lambda}{\lambda+\delta \beta^{2} v}\right)^{2}\right) .
\end{aligned}
$$

Thus, the initial guess of the value function is verified where

$$
\begin{array}{r}
\mu=\frac{\sigma_{\epsilon}^{2}+\lambda\left(\sigma_{h}^{2}+a_{\rho}^{2} \sigma_{H}^{2}\right)+\delta v\left(\sigma_{\epsilon}^{2}+\beta^{2}\left(\sigma_{h}^{2}+a_{\rho}^{2} \sigma_{H}^{2}\right)\right)}{1-\delta}, \\
v=\frac{\delta \beta^{2}-\lambda(1-\delta)+\sqrt{4 \lambda \delta \beta^{2}+\left(-\delta \beta^{2}+\lambda(1-\delta)\right)^{2}}}{2 \delta \beta^{2}} .
\end{array}
$$

The negative root of $v$ is rejected because any deviation of inflation and output form their steady-state values can only have a non-negative effect on the loss function. The value function is obtained by substituting $\mu$ and $v$ into the initial conjectured function.

Solving the optimisation problem with respect to $k_{t}$ for the same conjectured form of the optimal value function provides the first-order condition in (A.T). Thus, instrument substitutability is maintained as the first-order condition and consequently the corresponding value function, is independent of the instrument used. 
Moreover, for $z=1$, let $L_{F S}(\pi, y)$ denote the value function at $t$. When $i_{t}$ is the policy instrument, the Bellman equation is

$$
\begin{gathered}
L_{F S}(\pi, y)=\min _{i_{t}, y_{t+1}}\left\{E_{t}\left[\left(k_{t} / \ell_{\rho}+y_{t}(\beta+\theta)+\pi_{t}-i_{t}+H_{t}\right)^{2}+\delta L_{F S}\left(\pi_{t+1}, y_{t+1}\right)\right]\right\} \\
\text { s.t. } y_{t+1}=\phi y_{t}-a_{i}\left(i_{t}-\pi_{t}\right)-a_{\rho} k_{t} / \ell_{\rho}+h_{t+1}-a_{\rho} H_{t} \text { and } \pi_{t+1}=\pi_{t}+\beta y_{t}+\epsilon_{t+1} .
\end{gathered}
$$

We guess that $L_{F S}(\pi, y)$ takes the form $L_{F S}(\pi, y)=\mu_{1}+\mu_{2}\left(\mu_{3}+v_{1} \pi+v_{2} y\right)^{2}$. Solving the optimisation problem we derive the first-order condition

$$
i_{t}-\pi_{t}=\frac{k_{t}\left(1-\delta a_{i} a_{\rho} v_{2}^{2} \mu_{2}\right) / \ell_{\rho}+\delta a_{i} v_{2} \mu_{2}\left(\mu_{3}+v_{1} \pi_{t}\right)+y_{t}\left(\beta+\theta+\delta a_{i} v_{2} \mu_{2}\left(\beta v_{1}+\phi v_{2}\right)\right)}{1+\delta a_{i}^{2} v_{2}^{2} \mu_{2}}
$$

so that the Bellman equation yields

$$
\begin{aligned}
L_{F S}(\pi, y)= & \sigma_{H}^{2}+\delta\left(\mu_{1}+\mu_{2}\left(v_{1}^{2} \sigma_{\epsilon}^{2}+v_{2}^{2}\left(\sigma_{h}^{2}+a_{\rho}^{2} \sigma_{H}^{2}\right)\right)+\frac{\delta \mu_{2}}{1+\delta\left(a_{i} v_{2}\right)^{2} \mu_{2}}\right. \\
& \left(k_{t} v_{2}\left(a_{i}+a_{\rho}\right)-\mu_{3}-v_{1} \pi_{t}+y_{t}\left(a_{i} v_{2}(\beta+\theta)-v_{2} \phi-\beta v_{1}\right)\right)^{2} .
\end{aligned}
$$

The conjectured form of $L_{F S}(\pi, y)$ is satisfied, $\mu_{1}=\sigma_{H}^{2} /(1-\delta)$ while the remaining coefficients are zero. This implies $L_{F S}(\pi, y)=\sigma_{H}^{2} /(1-\delta)$.

Furthermore, solving the above optimisation problem with respect to $k_{t}$ provides the firstorder condition described in (A.2). As before, instrument substitutability is maintained.

\section{Proof of Lemma 3}

Focusing on extreme values of social preferences, consider that $z=0$ whereas $\zeta=1$. The output gap transition functions are described by (18) and (19) for each setting. The multi-period value functions are reduced to

$$
\begin{aligned}
& L_{M P}^{i}(\pi, y)=\delta E_{t}\left[\pi_{t+1}^{2}+\lambda\left(g^{i} y_{t}+h_{t+1}-a_{\rho} H_{t}\right)^{2}+\delta L_{M P}^{i}\left(\pi_{t+1}, y_{t+1}\right)\right] \\
& L_{M P}^{k}(\pi, y)=\delta E_{t}\left[\pi_{t+1}^{2}+\lambda\left(q^{k}\left(\pi_{t}+\beta y_{t}\right)+g^{k} y_{t}+h_{t+1}-a_{\rho} H_{t}\right)^{2}+\delta L_{M P}^{k}\left(\pi_{t+1}, y_{t+1}\right)\right],
\end{aligned}
$$

where $g^{i}=a_{y}-\theta\left(a_{i}+a_{\rho}\right), g^{k}=a_{y}$ and $q^{k}=a_{i}+a_{\rho}$. Let $L_{M P}(\pi, y)=\psi_{1}+\psi_{2} \pi^{2}+\psi_{3} \pi y+$ $\psi_{4} y^{2}$ the conjectured optimal value function. The undetermined coefficients $\psi_{2}, \psi_{3}$ and $\psi_{4}$ are positive as inflation and output gap move in the same direction and have a positive impact on $L_{M P}^{i}(\pi, y)$. To simplify the notation for the remaining of this proof, let $\sigma^{2}=\sigma_{h}^{2}+a_{\rho}^{2} \sigma_{H}^{2}$.

The conjectured form of $L_{M P}(\pi, y)$ is satisfied for:

$$
\begin{aligned}
& \psi_{1}^{i}=\delta\left(\psi_{1}^{i}+\sigma_{\epsilon}^{2} \psi_{2}^{i}+\sigma^{2} \psi_{4}^{i}\right)+\sigma_{\epsilon}^{2}+\lambda \sigma^{2}, \psi_{2}^{i}=1+\delta \psi_{2}^{i}, \\
& \psi_{3}^{i}=2 \beta\left(1+\delta \psi_{2}^{i}\right)+\delta \psi_{3}^{i} g^{i}, \psi_{4}^{i}=\beta^{2}\left(1+\delta \psi_{2}^{i}\right)+\beta \delta \psi_{3}^{i} g^{i}+\left(\delta \psi_{4}^{i}+\lambda\right)\left(g^{i}\right)^{2} ;
\end{aligned}
$$

and

$$
\begin{aligned}
& \psi_{1}^{k}=\delta\left(\psi_{1}^{k}+\sigma_{\epsilon}^{2} \psi_{2}^{k}+\sigma^{2} \psi_{4}^{k}\right)+\sigma_{\epsilon}^{2}+\lambda \sigma^{2}, \psi_{2}^{k}=1+\delta \psi_{2}^{k}+\delta q^{k}\left(\psi_{3}^{k}+q^{k} \psi_{4}^{k}\right)+\lambda\left(q^{k}\right)^{2}, \\
& \psi_{3}^{k}=2 \beta\left(1+\delta \psi_{2}^{k}\right)+\delta \psi_{3}^{k}\left(\beta q^{k}+g^{k}\right)+q^{k}\left(\beta \delta \psi_{3}^{k}+2\left(\beta q^{k}+g^{k}\right)\left(\delta \psi_{4}^{k}+\lambda\right)\right), \\
& \psi_{4}^{k}=\beta^{2}\left(1+\delta \psi_{2}^{k}\right)+\beta \delta \psi_{3}^{k}\left(\beta q^{k}+g^{k}\right)+\left(\delta \psi_{4}^{k}+\lambda\right)\left(\beta q^{k}+g^{k}\right)^{2} .
\end{aligned}
$$

Provided that $\psi_{2}, \psi_{3}$ and $\psi_{4}$ are positive, then $\psi_{2}^{i}<\psi_{2}^{k}$, and therefore $\psi_{3}^{i}<\psi_{3}^{k}$ and $\psi_{4}^{i}<\psi_{4}^{k}$. Consequently $\psi_{1}^{i}<\psi_{1}^{k}$ which implies $L_{M P}^{i}(\pi, y)<L_{M P}^{k}(\pi, y)$. As the value function is 
monotonic in $\zeta, i_{t}$ is the preferred instrument for any $\zeta \in(0,1]$ when monetary stability is socially desirable.

Consider now that $z=1$. Both settings attain the first-best for $\zeta=1$. For $\zeta=0$, the policy rule is given by (114) where $k=0$ or $i=0$ when the instrument is $i$ or $k$, respectively. In this case, inflation and output transition functions are the same in both settings where $\pi_{t+1}$ is given by the Phillips curve and $y_{t+1}$ by ([17). As before, the conjectured loss function is $L_{F S}(\pi, y)=\psi_{1}+\psi_{2} \pi^{2}+\psi_{3} \pi y+\psi_{4} y^{2}$ so that

$$
\begin{aligned}
& L_{F S}^{i}(\pi, y)=E_{t}\left[\left(y_{t}\left(\frac{a_{y}-\theta\left(a_{i}+a_{\rho}\right)+\beta M}{a_{i}}\right)+\pi_{t}\left(\frac{M}{a_{i}}\right)-H_{t}\right)^{2}+\sigma_{H}^{2}+\delta L_{F S}^{i}\left(\pi_{t+1}, y_{t+1}\right)\right] \\
& L_{F S}^{k}(\pi, y)=E_{t}\left[\left(y_{t}\left(\frac{a_{y}+\beta\left(a_{i}+a_{\rho}\right)+\beta M}{a_{\rho}}\right)+\pi_{t}\left(\frac{M+a_{i}}{a_{\rho}}+1\right)+H_{t}\right)^{2}+\delta L_{F S}^{k}\left(\pi_{t+1}, y_{t+1}\right)\right],
\end{aligned}
$$

where $\psi_{1}, \psi_{2}, \psi_{3}$ and $\psi_{4}$ are the undetermined coefficients. It can be verified that the conjectured loss function is satisfied in both settings and the coefficients can be determined as before. However, since the transition functions are the same, concluding about the instrument dominance can be simplified to the comparison of the loss functions at $t$. From the above expressions it is apparent that $a_{\rho} \leq a_{i}$ is a sufficient condition that guarantees $L_{F S}^{i} \leq L_{F S}^{k}$. Monotonicity of the value function in $\zeta$ implies that setting $i$ results in lower loss for any $\zeta \in[0,1)$ when financial stability is socially desirable. Thus, from the linearity of the social objective function in $z$, it follows that $i$ is the dominant instrument for a single policymaker.

The comparison between $L^{R}$ and $L^{S}$ is focusing on the financial stability as the former arrangement attains $L_{M P}\left(k_{f}, i_{f}\right)$. For $z=1$, the value functions are

$$
\begin{aligned}
& L_{F S}^{R}(\pi, y)=E_{t}\left[\left(\left(\frac{a_{\rho}+M}{a_{i}}+1\right)\left(\pi_{t}+\beta y_{t}\right)+\frac{a_{y}}{a_{i}} y_{t}-H_{t}\right)^{2}+\delta L_{F S}^{R}\left(\pi_{t+1}, y_{t+1}\right)\right] \\
& L_{F S}^{S}(\pi, y)=E_{t}\left[\left(\left(\frac{a_{i}+M}{a_{i}}\right)\left(\pi_{t}+\beta y_{t}\right)+\frac{a_{y}-a_{\rho} \theta}{a_{i}} y_{t}-H_{t}\right)^{2}+\delta L_{F S}^{S}\left(\pi_{t+1}, y_{t+1}\right)\right],
\end{aligned}
$$

where the output gap transition equations (II7) and (22), respectively. The conjecture of the value function considered is of the form $L_{M P}(\pi, y)=\psi_{1}+\psi_{2} \pi^{2}+\psi_{3} \pi y+\psi_{4} y^{2}$, where $\psi_{1}$, $\psi_{2}, \psi_{3}$ and $\psi_{4}$ are the non-negative undetermined coefficients.

The conjectured form of $L_{F S}^{R}(\pi, y)$ is satisfied for

$$
\begin{aligned}
& \psi_{1}^{R}(1-\delta)=\sigma_{H}^{2}+\delta\left(\sigma_{\epsilon}^{2} \psi_{2}^{R}+\sigma^{2} \psi_{4}^{R}\right), \psi_{2}^{R}(1-\delta)=\left(\frac{M+a_{\rho}}{a_{i}}+1\right)^{2}+\delta M\left(M \psi_{4}^{R}-\psi_{3}^{R}\right), \\
& \psi_{3}^{R}=2 \frac{\left(M+a_{\rho}+a_{i}\right)\left(M \beta+\phi+a_{\rho}(\beta+\theta)\right)}{a_{i}^{2}}+2 \beta\left(\psi_{2}^{R}-\left(\frac{M+a_{\rho}}{a_{i}}+1\right)^{2}\right), \\
& \psi_{4}^{R}=\left(\frac{M \beta+\phi+a_{\rho}(\beta+\theta)}{a_{i}}\right)^{2}+\beta^{2}\left(\psi_{2}^{R}-\left(\frac{M+a_{\rho}}{a_{i}}+1\right)^{2}\right)
\end{aligned}
$$


and

$$
\begin{aligned}
& \psi_{1}^{S}(1-\delta)=\sigma_{H}^{2}+\delta\left(\sigma_{\epsilon}^{2} \psi_{2}^{S}+\sigma^{2} \psi_{4}^{S}\right), \\
& \psi_{2}^{S}(1-\delta)=\left(\frac{M+a_{i}}{a_{i}}\right)^{2}+\delta\left(M-a_{\rho}\right)\left(\left(M-a_{\rho}\right) \psi_{4}^{S}-\psi_{3}^{S}\right), \\
& \psi_{3}^{S}\left(1-\delta a_{\rho} \theta\right)=2\left(\frac{(M \beta+\phi)\left(M+a_{i}\right)}{a_{i}^{2}}\right)+2 \beta\left(\psi_{2}^{S}-\left(\frac{M+a_{i}}{a_{i}}\right)^{2}\right)-2 \delta \theta a_{\rho}\left(M-a_{\rho}\right) \psi_{4}^{S}, \\
& \psi_{4}^{S}\left(1-\delta a_{\rho}^{2} \theta^{2}\right)=\left(\frac{a_{y}-a_{\rho} \theta}{a_{i}}\right)^{2}+\beta\left(\psi_{3}^{S}-\beta \psi_{2}^{S}\right) .
\end{aligned}
$$

However, comparisons between the value functions or even the coefficients obtained are inconclusive, as the dominant setting depends on the parameters of the model. In particular, when $\delta$ tends to $0^{+}$, the loss functions in (A.3) and (A.4) are equal to the interest rate rules for each setting as described in (20) and (21). Clearly, given the initial conditions for inflation and output gap, complete separation is the dominant arrangement due to the moderate adjustment of the instrument and given that any future effects are ignored. Moreover, for values of $\delta$ in the neighbourhood of $1^{-}$, the value function and consequently the overall dominance of a setting depends on the coefficient $\psi_{1}^{i}$. Comparing the value functions while avoiding indeterminacy, evaluation at $\delta=1$ yields that they depend on the volatility of the associated interest-rate rules and consequently on the volatility of the state variables. Specifically,

$$
\lim _{\delta \rightarrow 1^{-}} L_{F S}^{R}\left(\pi^{R}, y^{R}\right)=\operatorname{Var}\left[i^{R}\right]+\sigma_{H}^{2} \text { and } \lim _{\delta \rightarrow 1^{-}} L_{F S}^{S}\left(\pi^{S}, y^{S}\right)=\operatorname{Var}\left[i^{S}\right]+\sigma_{H}^{2}
$$

where the policy rules are given by $(201)$ and (2I), while the variances and covariance of inflation and output gap, denoted by $\operatorname{Var}\left[\pi^{j}\right], \operatorname{Var}\left[y^{j}\right]$ and $\operatorname{Cov}\left[\pi^{j}, y^{j}\right]$, are

$$
\begin{aligned}
& \operatorname{Var}\left[y^{j}\right]=\frac{2 \beta \sigma^{2}-\left(1+g^{j}\right) q^{j} \sigma_{\epsilon}^{2}}{\beta\left(1-g^{j}\right)\left(2\left(1+g^{j}\right)+q^{j} \beta\right)}, \quad \operatorname{Cov}\left[\pi^{j}, y^{j}\right]=-\frac{\beta^{2} \sigma^{2}+\left(1-g^{j}\left(g^{j}+q^{j} \beta\right)\right) \sigma_{\epsilon}^{2}}{\beta\left(1-g^{j}\right)\left(2\left(1+g^{j}\right)+q^{j} \beta\right)}, \\
& \operatorname{Var}\left[\pi^{j}\right]=-\frac{\beta^{2}\left(1+g^{j}\right) \sigma^{2}+\left(1-\left(g^{j}+2 q^{j} \beta\right)\left(1-g^{j}\left(g^{j}-1\right)\right)-\left(q^{j} \beta\right)^{2}\left(1-g^{j}\right)\right) \sigma_{\epsilon}^{2}}{q^{j} \beta\left(1-g^{j}\right)\left(2\left(1+g^{j}\right)+q^{j} \beta\right)} .
\end{aligned}
$$

Note also that $q^{R}=-M, q^{S}=-\left(M-a_{\rho}\right), g^{R}=0$ and $g^{S}=a_{\rho} \theta$. Provided that the stationarity conditions in Corollary $\square$ hold so that $M>a_{\rho}$ and $a_{\rho} \theta<1, \operatorname{Cov}\left[\pi^{j}, y^{j}\right]<0$ as expected. To demonstrate cases where partial separation is the dominant setting, suppose for simplicity that $\ell^{d}$ and $\ell^{s}$ have the same sensitivity to output gap so that $\rho_{t}$ is independent of $\theta$, limiting the effect that $\operatorname{Var}\left[y^{j}\right]$ has on financial stability. It follows that

$$
\begin{aligned}
& \frac{\partial \operatorname{Var}\left[y^{j}\right]}{\partial q^{j}}=-\frac{2\left(\sigma_{\epsilon}^{2}+\beta^{2} \sigma_{h}^{2}\right)}{\beta(2+q \beta)^{2}}<0, \quad \frac{\partial \operatorname{Cov}\left[\pi^{j}, y^{j}\right]}{\partial q^{j}}=-\left(\frac{\beta}{2}\right) \frac{\partial \operatorname{Var}\left[y^{j}\right]}{\partial q^{j}}>0, \\
& \frac{\partial \operatorname{Var}\left[\pi^{j}\right]}{\partial q^{j}}=-\left(\frac{1+q \beta}{q^{2}}\right) \frac{\partial \operatorname{Var}\left[y^{j}\right]}{\partial q^{j}}>0 .
\end{aligned}
$$

Since $q^{R}<q^{S}$ then $\operatorname{Var}\left[y^{R}\right]>\operatorname{Var}\left[y^{S}\right], \operatorname{Var}\left[\pi^{R}\right]<\operatorname{Var}\left[\pi^{S}\right]$ and $\operatorname{Cov}\left[\pi^{R}, y^{R}\right]<\operatorname{Cov}\left[\pi^{S}, y^{S}\right]$. Hence, although the interest-rate rule for partial separation is more responsive to changes in state variables as indicated by their coefficients in the policy rule, the adjustment of $i_{t}$ is such that the resulting volatility of the state variables imposes lower cost on the loss function given that $\lambda<1$ and $\beta<1$. Clearly, for large values of $q$ (i.e. high $a_{\rho}$ ), provided that stationarity conditions are satisfied, the resulting high $\operatorname{Var}\left[\pi^{S}\right]$ imposes a greater loss, which consequently becomes the inferior setting. 


\section{Proof of Proposition $\$$}

The proof focuses on $z=1$ as $L_{M P}^{R}=L_{M P}\left(i_{f}, k_{f}\right)$. In particular, a single policymaker attains the first-best outcome, and therefore is the dominant setting, when $\zeta$ is 1 . The output gap transition functions are given by (118) and (117) for each setting.

As before, when $\zeta=0$ and for the conjectured loss function of the form $L_{F S}(\pi, y)=$ $\psi_{1}+\psi_{2} \pi^{2}+\psi_{3} \pi y+\psi_{4} y^{2}$, the value functions at $t$ are

$$
\begin{aligned}
& L_{F S}^{i}(\pi, y)=E_{t}\left[\left(y_{t}\left(\frac{a_{y}-\theta\left(a_{i}+a_{\rho}\right)+\beta M}{a_{i}}\right)+\pi_{t}\left(\frac{M}{a_{i}}\right)-H_{t}\right)^{2}+\delta L_{F S}^{i}\left(\pi_{t+1}, y_{t+1}\right)\right] \\
& L_{F S}^{R}(\pi, y)=E_{t}\left[\left(y_{t}\left(\frac{a_{y}+\beta\left(a_{i}+a_{\rho}\right)+\beta M}{a_{i}}\right)+\pi_{t}\left(\frac{M+a_{\rho}}{a_{i}}+1\right)-H_{t}\right)^{2}+\delta L_{F S}^{R}\left(\pi_{t+1}, y_{t+1}\right)\right] .
\end{aligned}
$$

Although it can be verified that the conjectured loss function is satisfied in both settings, since inflation and output gap transition functions are the same as described by the Phillips curve and (117), concluding about the dominance is simplified to the comparison of $L_{F S}^{j}(\pi, y)$ at $t$. From the above expressions it is clear that $L_{F S}^{i}<L_{F S}^{R}$. Provided that the value function is monotonic in $\zeta$, then $L_{F S}^{i}<L_{F S}^{R}$ for any $\zeta \in(0,1]$. Hence, from the linearity of the aggregate loss function in $z$, a unique value $\widetilde{z}$ exists such that $L^{i R}(\pi, y)>0$ for $z \in(0, \widetilde{z})$ and $L^{i R}(\pi, y)<0$ for $z \in(\widetilde{z}, 1)$. 